http://jmscr.igmpublication.org/home/

ISSN (e)-2347-176x ISSN (p) 2455-0450

crossref DOI: https://dx.doi.org/10.18535/jmscr/v7i8.51

Journal Of Medical Science And Clinical Research

IGM Publication

An Official Publication of IGM Publication

\title{
Use of Polyetylene Glycolenema in Patients on Hemodialysis Patients
}

Author

\author{
Dr Sanju Rajappan \\ Department of Medicine, PIMS, Pondicherry, India \\ *Corresponding Author \\ Dr Sanju Rajappan
}

Department of Nephrology, Malabar medical college, Modakkallur, Calicut, Kerala 673323, India

\begin{abstract}
Colonoscopy is a frequently performed procedure in the current era for evaluation of colitis and large bowel diarrhea. As a preparation for colonoscopy the patients are prescribed an enema which is most commonly a polyethylene glycol (PEG). This is usually given in a solution of about 2 liters and repeated if necessary. Since End Stage Renal disease (ESRD) patients on hemodialysis are not advised to consume large quantities of fluids, a patient undergoing colonoscopy is usually given inadequate preparation and subsequently inadequate radiological data. Here we have studied clinical and biochemical parameters of 5 patients who had to undergone colonoscopy or Contrast enhanced CT scan of the abdomen and our results show that the usage of Polyethylene solutions do not cause any increase in weight gain or are associated with dyselectrolytemia.
\end{abstract}

\section{Introduction}

Colonoscopy and contrast enhanced CT is frequently performed procedure in the current era for evaluation of colitis, large bowel diseases and for evaluation of abdominal pathologies. As a preparation for colonoscopy and CECT the patients are prescribed an enema which is most commonly a polyethylene glycol (PEG) in the current era. This is usually given in a solution of about 2 liters and repeated if necessary. Since End Stage Renal disease (ESRD) patients on hemodialysis are not advised to consume large quantities of fluids, a patient undergoing such investigative processes is usually given inadequate preparation and subsequently inadequate radiological data are obtained. Here we have studied clinical and biochemical parameters of 5 patients who had to undergone colonoscopy or Contrast enhanced CT scan of the abdomen.

\section{Review of Literature}

In the current era where more patients are being detected as End Stage Renal Disease and continued on dialysis whilst waiting for transplant, colonic pathology like colitis, carcinoma, angiodysplasias in this population is a common occurrence. The occult blood may be detected as positive due to various factors like use of heparin during dialysis or the occurrence of angiodysplasias in the colon, these patients would warrant a colonoscopy for accurate identification of the lesions. In order to achieve a good colonoscopy an adequate preparation is necessary with either a phosphate enema or polyethylene glycol enema. Oral sodium phosphate as a preparatory agent for colonoscopy is not to be used in the setting of GFR $<60 \mathrm{ml} / \mathrm{min}^{1}$. Hence PEG enema is preferred in ESRD patients for preparation of colonoscopy. There have been fatal 
complications with regard to dysnatremia when used in dialysis patients .Hence there is a lot of apprehension in its use, also the use of polyethylene requires large amount of fluids for dilution, about 2 liters for every sachet (17gms), consumption of such large quantity of fluids can cause CCF in patients with hemodialysis. ${ }^{3}$

\section{Aims and Objectives}

To evaluate whether the use of PEG enema is associated with

1) Dyselectrolytemia, and

2) weight gain in dialysis patients

\section{Materials and Methods}

Study Design: clinical observational study

Sample Size: 5 patients

Method: Patients who were hemodynamically stable and on thrice weekly dialysis were chosen for the study. The indication of colonoscopy and CECT were varied and it was advised in consultation with a gastroenterologist.

All the chosen patients underwent hemodialysis at least 4 hours before the PEG enema was given and the procedure (colonoscopy and CECT) were performed after 8-12 hours. The patients underwent dialysis 24 hours after the procedure.

The body weight of the patient was monitored pre HD and on the day of the procedure (colonoscopy/ CECT).

Serum electrolytes (sodium/ potassium/ chloride) were monitored pre HD before the enema and pre HD after the enema.

Study Period: 6 months (January 2014 to June 2014).

\section{Inclusion Criteria}

- Adult chronic kidney disease patients on maintenance hemodialysis (HD) for at least 3 months.

\section{Exclusion Criteria}

- H/o cardiac interventions (CABG/PTCA)

- Acute on chronic kidney disease

- Serum Sodium levels <135 and >150 $\mathrm{mmol} / \mathrm{L}$

- History of Arrhythmias
Analysis of Data: since the number of patients were small and this study was only to assess the safety of the procedure

\section{Observations and Results}

Total of 5 patients (5 males) completed the study.

Table 1: Serum pre HD sodium in $\mathrm{mmol} / \mathrm{l}$

\begin{tabular}{|l|c|c|}
\hline Subject & Before procedure & After procedure \\
\hline 1 & 137.9 & 137.4 \\
\hline 2 & 142.6 & 142.7 \\
\hline 3 & 139.0 & 140.0 \\
\hline 4 & 138.4 & 139.2 \\
\hline 5 & 142.8 & 141.4 \\
\hline
\end{tabular}

Table 2: Serum pre HD potassium in $\mathrm{mmol} / \mathrm{L}$

\begin{tabular}{|l|c|c|}
\hline Subject & Before procedure & After procedure \\
\hline 1 & 3.7 & 3.7 \\
\hline 2 & 4.2 & 4.2 \\
\hline 3 & 3.9 & 4.0 \\
\hline 4 & 3.8 & 3.9 \\
\hline 5 & 4.2 & 4.1 \\
\hline
\end{tabular}

Table 3: Serum pre HD chloride

\begin{tabular}{|l|c|c|}
\hline Subject & Before procedure & After procedure \\
\hline 1 & 107.9 & 107.4 \\
\hline 2 & 102.6 & 102.7 \\
\hline 3 & 109.0 & 100.0 \\
\hline 4 & 108.4 & 109.2 \\
\hline 5 & 102.8 & 101.4 \\
\hline
\end{tabular}

Table 4: Mean of Blood pressure

\begin{tabular}{|l|c|c|c|c|}
\hline SUBJECT & \multicolumn{2}{|c|}{ SBP (mm of Hg) } & \multicolumn{2}{c|}{ (DBP mm of Hg) } \\
\cline { 2 - 5 } & $\begin{array}{c}\text { Pre HD } \\
\text { before } \\
\text { enema }\end{array}$ & $\begin{array}{c}\text { Pre HD } \\
\text { after } \\
\text { enema }\end{array}$ & $\begin{array}{c}\text { Pre HD } \\
\text { before } \\
\text { enema }\end{array}$ & $\begin{array}{c}\text { Pre HD } \\
\text { after } \\
\text { enema }\end{array}$ \\
\hline 1 & 145 & 147.5 & 88 & 87.5 \\
\hline 2 & 144.4 & 150.2 & 88 & 86.66 \\
\hline 3 & 147.75 & 139.5 & 83.5 & 83.25 \\
\hline 4 & 137.11 & 129.11 & 77.33 & 74.44 \\
\hline 5 & 142.5 & 145 & 79.75 & 88.5 \\
\hline
\end{tabular}

Table 5: Weight Gain

\begin{tabular}{|l|c|c|c|}
\hline Subject & \multicolumn{3}{|c|}{ Weight Gain (Kg) } \\
\cline { 2 - 4 } & $\begin{array}{c}\text { Pre } \\
\text { enema } \\
\text { (pre HD) }\end{array}$ & $\begin{array}{c}\text { Post procedure } \\
\text { weight gain/loss }\end{array}$ & $\begin{array}{c}\text { Post } \\
\text { procedure } \\
\text { (pre-HD) }\end{array}$ \\
\hline 1 & 2.64 & 0.3 & 2.44 \\
\hline 2 & 3.46 & 0.8 & 3.0 \\
\hline 3 & 3.57 & 0.4 & 2.9 \\
\hline 4 & 1.32 & 0.2 & 1.1 \\
\hline 5 & 3.42 & 0.9 & 2.8 \\
\hline
\end{tabular}




\section{Discussion}

Chronic kidney disease (CKD) is often an asymptomatic condition resulting in dependence on renal replacement therapy at a later stage. Although, renal transplantation is an excellent option, there are shortcomings including lack of donors and cost. Dialysis is then adopted for survival in these individuals.

Disorders of the colon and abdomen are seen in patients on dialysis at a frequency of the regular population and some disorders are specifically seen in this population

With the advent of new treatment modalities it was necessary for better visualization of the colon and abdomen and hence the need for contrast CT and colonoscopy with preparation of the colon for facilitation. The enema that were used were phosphate based and resulted in retention of phosphorus in dialysis patients or lactulose based that did not ensure adequate preparation. The use of PEG enema in normal individuals resulted in better preparation and better radiological visualizations. However the PEG enema that was given orally had to be mixed with 2 liters of fluid for adequate outcomes, this quantity of fluid consumption would result in excessive weight gain and dyselectrolytemia, especially hyponatremia (dilutional) and hypernatremia (loss of fluids) in dialysis patients. Data on use of these enema in dialysis population is lacking though many studies did include CKD patients.

Here in this study we have tried to analyze if the use of this enema was safe for dialysis patients, its effect on hypertension, weight gain and electrolytes.

The pre HD blood pressure before giving oral 2 liter PEG enema was taken and compared with pre HD blood pressure after the procedure (CECT and colonoscopy), there was no change noted in the measurement of BP. The weight of the patient also did not change much, this may be due to the loss of fluids through the stools. There was weight gain in all patients but this gain was expected in dialysis patients. The serum electrolytes pre HD before the enema and after did not alter significantly.

The number of patients studied was small and hence statistical significance was not reached. We hope that there will be large randomized controls to ascertain further evaluation.

\section{Conclusion}

The use of PEG enema for bowel preparation in dialysis patients is safe and not associated with significant dyselectrolytemia and weight gain, however larger trials are needed.

Sources of support in the form of grants: None.

\section{References}

1. Eliot C. Heher, ${ }^{*}$ Samuel O. Thier, ${ }^{* \dagger}$ Helmut Rennke, $\$$ and Benjamin D. Humphreys: Adverse Renal and Metabolic Effects Associated with Oral Sodium Phosphate Bowel Preparation :Clin J Am SocNephrol : 1494 -1503, 2008

2. Ayus JC, Levine R, Arieff AI: Fatal dysnatraemia caused by electivecolonoscopy. BMJ 2003;326:382-4.

3. Granberry MC, White LM, Gardner SF. Exacerbation of congestive heart failure after administration of polyethylene glycol-electrolyte lavage solution. Annpharmacother 1995;29:1232-

4. H. Katsanos, D.K. Christodoulou, Margarita Economou, Marina Rizou, Ioanna Theodorou H. Pappas, K.C. Siamopoulos :Colonoscopy outcome, safety and efficacy of colon cleansing in chronic renal failure :ANNALS OF GASTROENTEROLOGY 2003, 16(1):5359 


\author{
List of Abbreviations \\ CCF- Congestive cardiac failure \\ HD - Hemodialysis \\ ESRD-end stage renal disease \\ $\mathrm{WG}$ - weight gain \\ $\mathrm{Na}$ - sodium \\ K-potassium \\ Cl- chloride \\ BP- blood pressure \\ L - Liter \\ $\mathrm{mm}$ of $\mathrm{Hg}$ - Milli-meters of Mercury \\ SBP - Systolic blood pressure \\ DBP - Diastolic blood pressure \\ CKD - Chronic Kidney Disease \\ No. - Number \\ Fig - Figure
}

